Material Properties

\title{
Development of Modified Arcan Fixture for biaxial loading response of fiber-reinforced composites
}

\author{
P. Hao ${ }^{\text {a }}$, I. Ud Din ${ }^{\mathrm{b}}$, S. Panier ${ }^{\mathrm{a}, *}$ \\ ${ }^{a}$ Laboratoire des Technologies Innovantes, LTI-EA 3899, Université de Picardie Jules Verne, Amiens, 80025, France \\ ${ }^{\mathrm{b}}$ Research Center for Modeling \& Simulation (RCMS), National University of Sciences and Technology (NUST), Sector H-12, Islamabad, Pakistan
}

\section{A R T I C L E I N F O}

\section{Keywords:}

Woven composite

Modified Arcan fixture

Multiaxial loading

FEM

Shear strength

\begin{abstract}
A B S T R A C T
A Modified Arcan Fixture (MAF) was developed to study the biaxial mechanical behavior of fiber reinforced composites. The MAF was calibrated compared with standard ASTM tests for an epoxy/twill woven-ply laminate. Material properties obtained with ASTM tests are implemented in ABAQUS to find the optimal notch radius that creates the most uniform stress state in gauge area. The optimized configuration of Arcan specimen was adopted to design the entire fixture numerically in preload and load steps to avoid plastic deformation. Stress concentration factor was considered in Arcan specimen under tensile loading. Biaxial experimental data for woven-ply composite in different loading angles was obtain with the MAF. Failure modes under biaxial loading show that fibers rotated towards the principle tensile direction and failure was caused by excessive stress which reached fiber limit. The ultimate shear strength corrected by considering the fiber rotation effect are in good agreement with ASTM standard results.
\end{abstract}

\section{Introduction}

Mechanical properties for fiber reinforced polymers (FRPs) can be determined by standard tests such as American Society for Testing and Materials (ASTM), Association Française de Normalisation (AFNOR), International Organization for Standardization (ISO) and Japanese Industrial Standards (JIS). Special cares as suggested by ASTM D6856 [1] are made to characterize woven composites by refining the specimen dimension according to the size of Repeat Unit Cell (RUC). The mechanical properties along and perpendicular to reinforcement direction has been fully understood. However, in applications of multiaxially loaded laminates, intra strain occurs and shear phenomena limit the material performance. Under biaxial loading conditions, the damage often evolves with coupled tension (compression)/tension and tension (compression)/shear. The World-Wide Failure Exercise (WWFE-I, II and III) $[2,3]$ reported about benchmarking failure criteria in continuous FRPs under two-dimensional (2-D) stresses and also gave details of the input data for benchmarking triaxial failure criteria. It revealed that theoretical results should be analyzed and validated under multiaxial loadings. Therefore, developing a simple and robust device to supply the reliable material property data and to validate the multiaxial response becomes much more meaningful than ever.
Multiaxial loadings can be achieved by (1) off-axis specimen without a special clamping system, (2) tubular and (3) cruciform specimens [4], as shown in Fig. 1a-b. Internal multiaxiality achieved with off-axis specimens under uniaxial tension/compression loading were experimentally investigated [5]. Tubular specimens [6] are capable to subject combined tension/compression, internal pressure and/or torsional loading while cruciform specimens [7] can subject biaxial tension-tension, tension-compression and compression-compression loading. The pressure vessels form of tubular specimens cannot represent typical laminate planar structures as they are manufactured by filament winding yet the planar specimens are prepared in another different processes. The machining of the cruciform specimens needs special care to the corner fillet to insure that failure occurs inside the gauge section and reduction of the thickness. Furthermore, the tests require a sophisticated biaxial test machine.

As Iosipescu, V-notch rail shear and Arcan tests are gaining their popularity in identifying in-plane shear properties for FRPs, improvement and modification in fixture have been made to acquire high quality data $[8,9]$. Compared to Iosipescu configuration, the larger range of shear dominated stress states can be achieved with Arcan specimen. Besides, a relatively simple manner to control specimen alignments and to conduct biaxial loading test is available although Arcan specimen was

\footnotetext{
* Corresponding author.

E-mail addresses: pei.hao@u-picardie.fr (P. Hao), israr.rcms@rcms.nust.edu.pk (I.U. Din), stephane.panier@u-picardie.fr (S. Panier).
} 
originally designed to study the shear response of polymers. It has been modified as a separated grip and a butterfly-shaped specimen version [10] used to investigate the failure of fiber reinforced material under bi-axial loading [11]. Different types of Arcan fixture system have been modified to ensure reliable parameters obtained under biaxial loads [12-16]. A Modified Arcan Fixture (MAF) has been used to determine the tension/compression-shear failure envelope with a modified version of the butterfly specimen and the failure observed at the connecting pin holes is a common issue [12]. Since there is no available standard for Arcan test for biaxial loading, different specimen dimensions such as the notch angle and notch root radius under shear are generally adopted and studied in published literature [13].

The problems of engineering and mathematical physics can be solved by a numerical method, the finite element method (FEM), with subdividing a large system into smaller, simpler parts. Typical problem remains in many areas such as structural analysis, heat transfer, fluid flow, electromagnetic potential, field of optics and biomedical engineering [8,13,17-20]. Many models were implemented to study behavior of FRPs. Liu et al. [18] used mesoscopic voxel models to predict linear and non-linear behavior of 3D woven composite. FEM is performed for the influence of parameters of FRPs during infusion process [17]. Based on FEM, adhesive wear in uni-directional (UD) reinforced carbon thermoplastic polyetherimide composite laminate was studied [19]. A modified V-notch rail shear fixture was developed and evaluated compared with the standardized one by using FEM [8]. The notch root and radius for Arcan specimen were studied numerically under shear and biaxial loading [13].

The aim of the present paper is to re-design the Arcan fixture and optimize the specimen geometry to obtain a reliable experimental data with specimen rupture in the gauge zone. Several improvements have been achieved with the guide unit and additional clamping jaws. A full material card was obtained for epoxy/twill woven-ply laminate by using this MAF with loading angles in pure tensile and shear. The material properties were corrected by considering stress concentration factor and fiber rotation effect. Results were highly in correspondence with experimental data followed by standard ASTM tests. To authors knowledge, rare multiaxial experimental data for woven ply laminate is available for model validation in the open literature. The design of an advanced fixture for applying biaxial loading is still highly demanded.

In this paper, at first the modification for Arcan fixture was presented as well as the optimal dimension of specimen. Secondly, the entire fixture including the specimen was examined in FEM within commercial software ABAQUS ${ }^{\circledR}$. The stresses were evaluated for the specimen under preload and tension steps. Von Mises stresses against yield stresses of each components of fixture were investigated. The stress distribution between notch roots affected by notch radius was studied under biaxial loading. Lastly, an experiment investigation of the MAF under different loading angles was reported. The mechanical parameters obtained with the MAF were compared to the ones with ASTM standard tests. The effect of stress concentration on Ultimate Tensile Strength (UTS) under loading angle $0^{\circ}$ and fiber rotation on shear strength under loading angle $90^{\circ}$ was discussed. Results were corrected and compared with ASTM D3039 [23] and ASTM D3518 [24].

\section{The Modified Arcan fixture and specimen}

\subsection{The modified Arcan apparatus for biaxial tension(compression)/ shear loading}

Arcan specimen was originally designed to study the shear response of polymers. In this paper, a MAF was designed and fabricated to study the mechanical response including damage accumulation and plasticity of the textile reinforced composite under biaxial loads. The proposed method using a MAF has several modifications.

Fig. 2 shows the modified Arcan clamp system and the butterfly shaped specimen. Compared with the original one proposed by Arcan et al. [25], The modified test fixture is equipped with guide units that increased the stiffness of the apparatus. Two guide columns were considered to prevent the bending during the test to insure in-plane stress states. With the designed slideways, specimens can be mounted without handling difficulties, besides, the misalignments were eliminated during the tests. Low-friction slideways are suggested by using commercially available clearance-free guide units with a high accuracy grade linear bushings SM16GU, and shaft diameter was chosen as $16 \mathrm{~mm}$. The modified fixture was made of aluminum alloy T7351 plates (thickness of $50 \mathrm{~mm}$ ) for highly stressed structural parts within a circular platform (diameter of $162 \mathrm{~mm}$ ).

Arcan specimens were attached on the inner platform which is coaxial with the loading head between two identical halves of the Arcan fixture with ten $8 \mathrm{~mm}$ diameter hex socket bolts in the region far from the gauge zone (see Fig. 3). The load can be transferred through handtightened bolts and gripping jaws from fixture to the butterfly specimen. In this configuration, tightening ten gripping bolts can decrease stresses around holes significantly, but inevitably, at a price of taking more time on assembling each specimen. Therefore, six bolts on the outside ring overlapping with the ring of Arcan fixture halves only play a

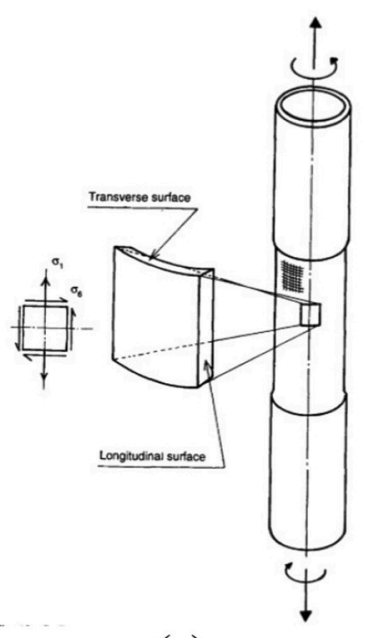

(a)

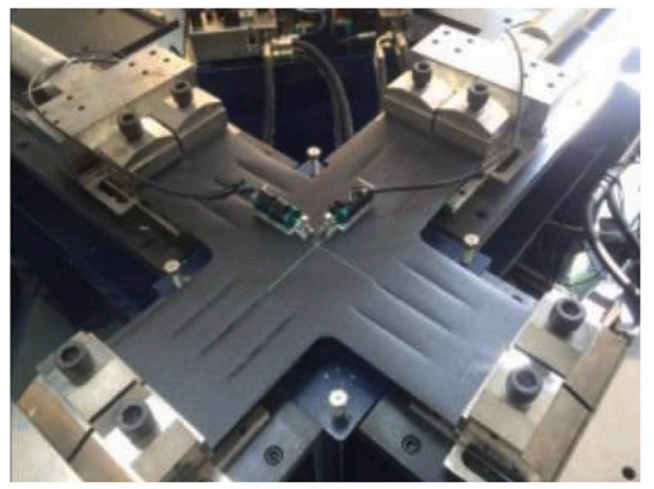

(b)

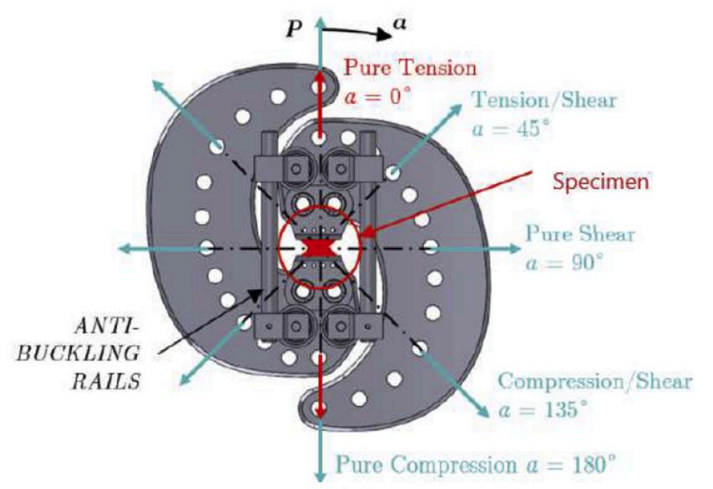

(c)

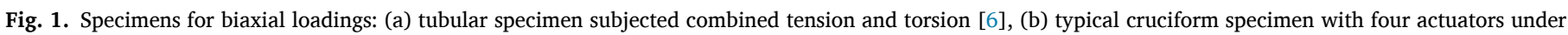
biaxial tension-tension [7] and a modified Arcan specimen [26]. 


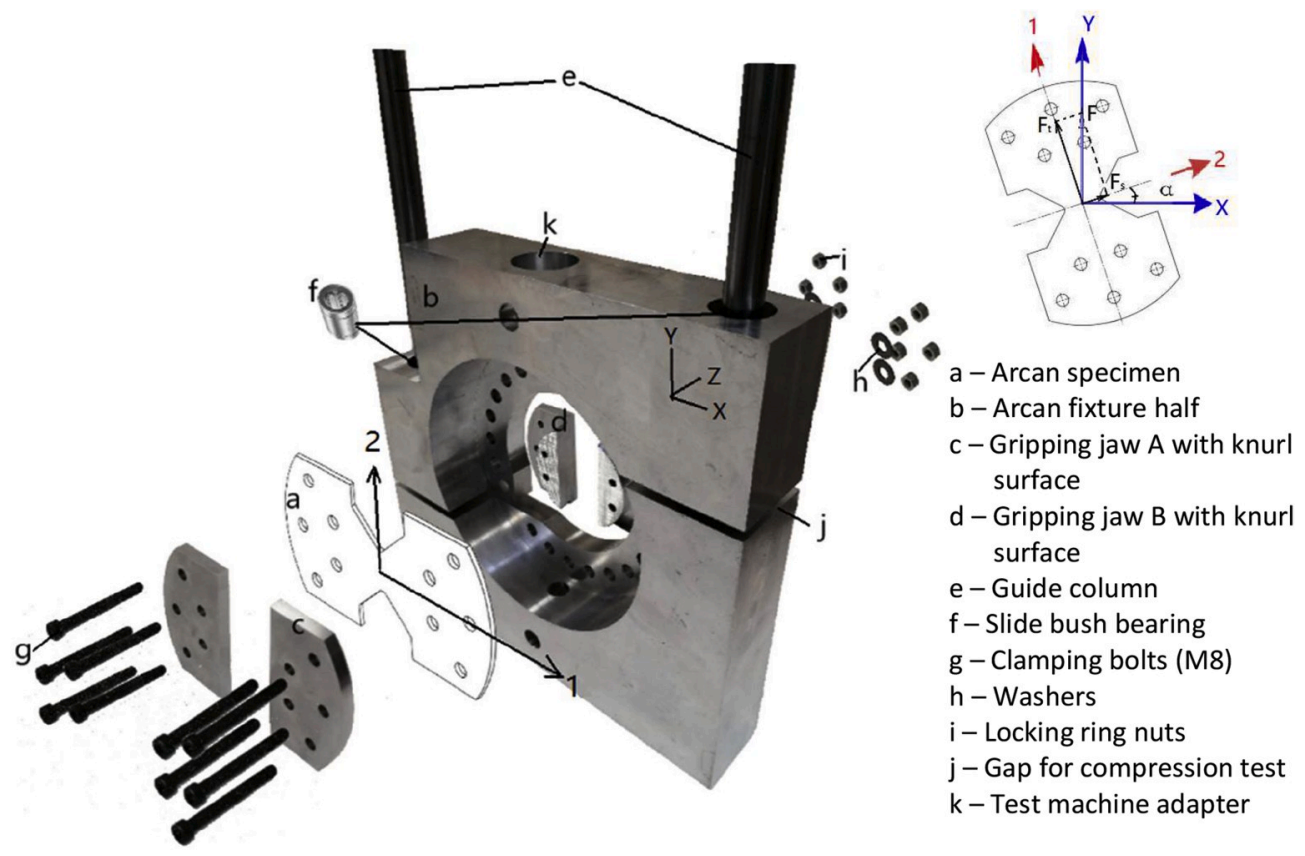

Fig. 2. Modified Arcan clamp system and specimen.

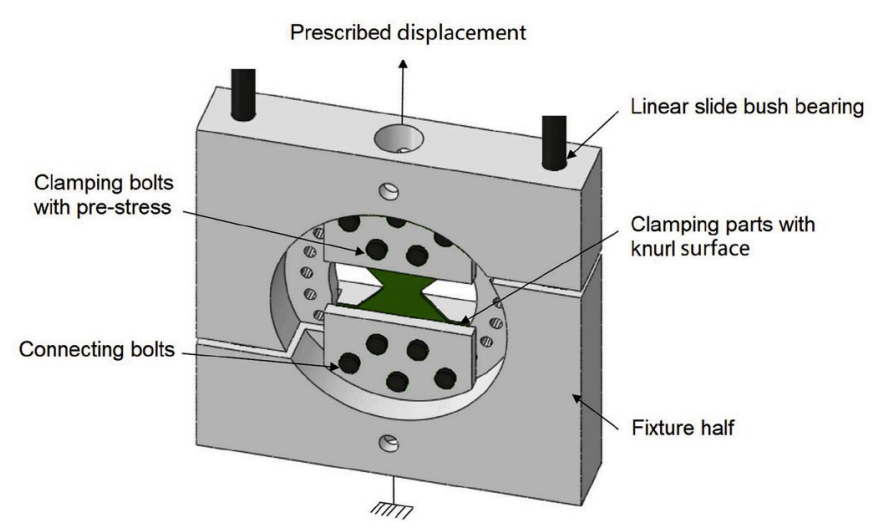

Fig. 3. Boundary conditions and contact pairs adopted in Arcan fixture model.

role of connecting gripping jaws and Arcan specimen without tightened. It becomes easier to disassemble and change loading direction of the precharged specimen without inducing new damage to it. The adhesion coefficient of the clamping surface was increased by creating structural surfaces as knurl pattern on gripping jaw part A and B so that specimens with various thicknesses can be clamped firmly. The gripping jaws and clamping bolts avoid the rotation of specimen effectively and transfer the loads evenly from tensile machine to specimen.

With holding a gap of $5 \mathrm{~mm}$ by a wedge (Fig. 2j), compression tests can be conducted without buckling thanks to the guide units. By changing the angle of Arcan specimen, biaxial stress states can be obtained, which leads that:

$F_{t}=F \cdot \cos \alpha$

$F_{s}=F \cdot \sin \alpha$

where $F_{\mathrm{t}}$ and $F_{\mathrm{s}}$ are the tensile and shear loads decomposed from applied load $F$ and $\alpha$ denotes the angle between $\mathrm{x}$-axis and 2-axis shown as in Fig. 2.

\subsection{Arcan specimen configuration}

The Arcan specimens made by epoxy/twill with thickness of $2.5 \mathrm{~mm}$ were cut roughly by a waterjet machining system and then finely grinded and drilled carefully to the final dimension by hand to avoid delamination caused by the water pressure during machining. The diameter $L$ was chosen as $160 \mathrm{~mm}$ according to the circular platform on the Arcan fixture. The width of specimen $W$ is $90 \mathrm{~mm}$ and the gauge length $d$ between two notch roots is $25 \mathrm{~mm}$. Ten holes with diameter $8 \mathrm{~mm}$ was drilled to match the gripping jaws and Arcan fixture halves. Parameters in gauge and notch area were studied to specify Arcan specimen dimension.

\section{Gauge length and width}

Gauge length (between notch roots) and width (along 1-axis) are borders of the red zone shown in Fig. 4. The gauge zone was determined and fixed in this study. As suggested in the ASTM standard tensile tests for woven composites, the size of RUC is an essential factor needed to be considered in choosing the sample dimension. Therefore, two times of RUC width $8 \mathrm{~mm}$ was chosen for gauge width. The width here does not affect the specimen configuration but was used to examine and ensure the stress and strain uniformity in gauge zone. Furthermore, the gauge length plays a more important role in the specimen dimension and Ref [10] has given optimal values of the dimension parameters governed by the ratios. Researchers have suggested different length. As the gauge length is too large, failure may not occur in the gauge zone and often initiate in the area of clamp holes caused by the fiber rotation which leads to delamination of the laminate [26]. Therefore, gauge length was chosen as the larger value of 1 ) standard tension test specimen width $25 \mathrm{~mm}$ and 2) two times of the size of RUC.

\section{Notch angle and radius}

Optimal notch angle and radius producing plane stress were also suggested by Arcan for fiber reinforced material (FRM) specimen for shear in a ratio form [10].

$\frac{d}{w}=\frac{d}{\sqrt{2} r}=5$ 


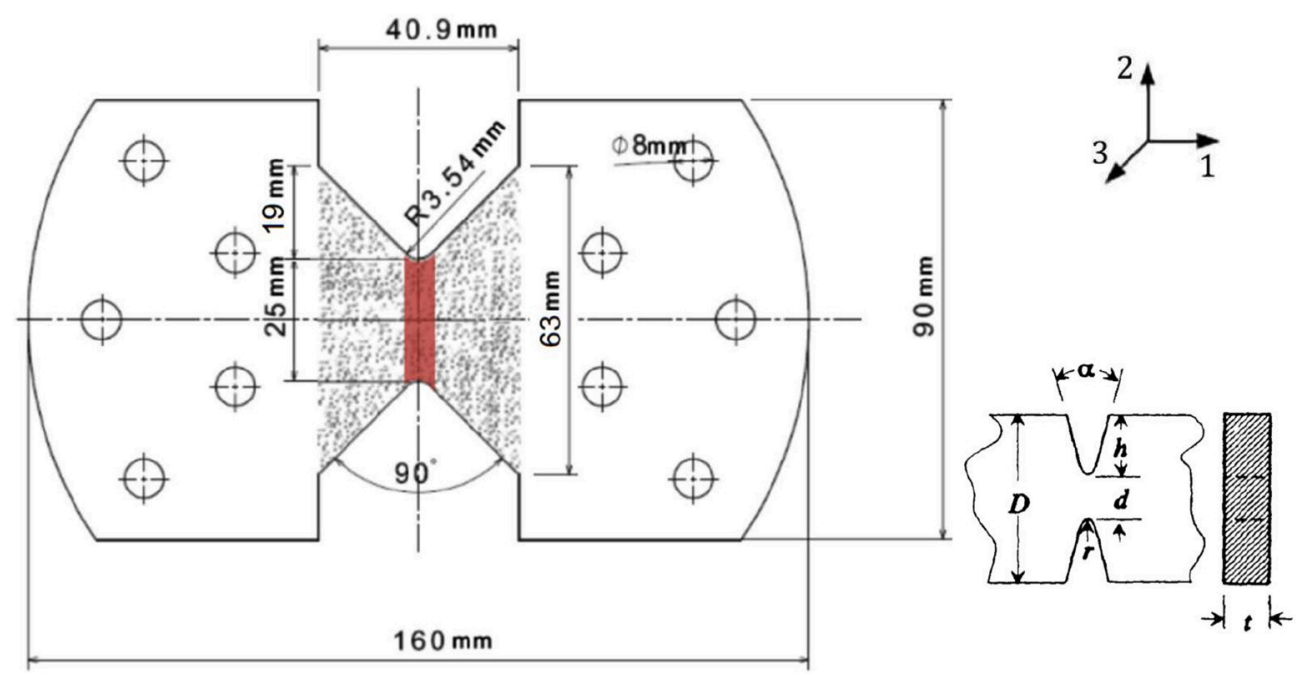

Fig. 4. Optimized dimension of Arcan specimen for the balanced twill composite.

where geometrical parameters $d, w$ and $r$ are length between the notch roots, width of notch root and notch radius respectively.

Notch angle of $90^{\circ}$ was suggested in ASTM D5379 for Iosipescu type specimen. Ref [13] summarized the optimum notch angle values in the published literatures. For transverse isotropic specimen as twill balanced woven composites studied in this work, optimum notch angle was chosen as $90^{\circ}$. Adams and Walrath [27] have also given notch angle of $90^{\circ}$ when $E_{11} / E_{22}=1$. Therefore, specimens with a notch angles, $90^{\circ}$ have been used.

Notch root radius has influence on the stress distribution in the gauge zone. Adams and Walrath [27] studied three different notch-root radii: $0,0.64$, and $1.27 \mathrm{~mm}$ for Iosipescu shear specimen, and pointed out that as the notch-root radius increases, the location of maximum shear stress tends to move away from the root of each notch toward the nearest inner loading point on Iosipescu shear specimen. K. W. Gan [12] has adopted notch radius $5 \mathrm{~mm}$ among three $(0.7,5$ and $10 \mathrm{~mm})$ to encourage premature or unexpected failure. Five radii $(0,1.27,2.38,4.78$ and $7.19 \mathrm{~mm}$ ) with a notch angle $90^{\circ}$ have been studied in Ref. [13]. For gauge length of $25 \mathrm{~mm}$, radius was calculated as $3.54 \mathrm{~mm}$ according to the ratios proposed by Arcan [10] and the stress uniformity was investigated with different radii in FEM section.

\section{Results and discussion}

\subsection{Evaluation of the MAF with finite element analysis}

The FEM was adopted to investigate the suitability of the MAF. The stress analysis of the specimen and whole test fixture was done by imposing a fasten force on the clamping unit. Furthermore, the connecting holes on both the test fixture and clamping parts were evaluated under tensile loading with normalized stress against yield stresses as well as the bolts. The stress distribution in the gauge area of Arcan specimen was examined according to various notch radius $(0,1.27,2.38$, $3.54,4.78$ and $7 \mathrm{~mm}$ ) with a fixed notch angle $90^{\circ}$.

\subsubsection{Finite element model}

Simulations were performed by using the finite element software ABAQUS/Explicit, which is established to analyze complex non-linear contact problems. To ensure the solving of quasi static problems, some special considerations are required to keep inertial forces insignificant in a state of dynamic equilibrium in an accelerated process. In fast loading cases, loading rates are increased with remaining the quality of the quasi-static solution. Smooth amplitude curves were applied to ensure that changes in velocity and displacement are smooth. It also helps to avoid the noise and inaccurate solutions introduced by sudden stress shock waves. The time required for a quasi-static solution with explicit solver is estimated with the lowest mode frequency of corresponding structure. Therefore, frequency procedure in Abaqus/Standard was used to approximate the natural frequencies of different parts of the MAF with the lowest of $45 \mathrm{~Hz}$ in the guide columns, which corresponds to a period of $22 \mathrm{~ms}$. To be certain a truly quasi-static solution, the period was amplified 10 times. The history energies were studied to evaluate the quasi-static response at the end of process.

Fig. 3 shows the geometric model with prescribed boundary conditions. A uniaxial displacement-controlled loading was applied with the other fixture half encastred. Part-independent method was used to discrete the model by tetrahedral element C3D4 for fixture halves and hexahedral element C3D8 for Arcan specimen, bolts, clamping units and guide columns. The element size has been matched within the contact area. The total number of elements was 1,700,733 and Degrees Of Freedom (DOF) of the model was 1,121,058. In the mechanical contact analysis, two contact properties were considered. A general contact interaction property refers to frictionless to the tangential motion and a penalty-based contacts for the knurl surface of the clamping units so that the realistic contact between specimen and clamping jaws was well simulated. The contact surfaces between connecting bolts and holes located on fixture halves, specimen and clamping jaws were assumed as frictionless.

The linear elastic materials were used in the finite element analysis because the irreversible plastic deformation is not considered in the whole MAF system. We adopted alloy 7075-T7351 to fabricate the MAF thanks to its fair machinability and superior strength (Table 1). It is widely utilized by the aircraft and ordnance industries as it offers the highest strength of the common screw machine alloys. Socket cap screws and nuts M8 class 12.9 with a yield strength of $1100 \mathrm{MPa}$ were used (Table 2). In this section, instead of woven composite, a transverseisotropic carbon fiber epoxy laminate with high elastic modulus on 1axis was chosen as the Arcan specimen (Table 3) to exploit the maximum capability of the MAF.

Because the connecting holes on the contact surfaces of fixture halves surrounded by clamping jaws are not accessible during the entire test

Table 1

Isotropic mechanical parameters for aluminum alloy T7351 and steel.

\begin{tabular}{llllll}
\hline Material & $\begin{array}{l}\text { Density }(\mathrm{g} / \\
\left.\mathrm{cm}^{3}\right)\end{array}$ & $\begin{array}{l}E \\
(\mathrm{GPa})\end{array}$ & $\nu$ & $\begin{array}{l}\text { Yield strength } \\
(\mathrm{MPa})\end{array}$ & $\begin{array}{l}\text { UTS } \\
(\mathrm{MPa})\end{array}$ \\
\hline T7351 & 2.81 & 72 & 0.33 & 435 & 505 \\
Steel & 7.82 & 206.8 & 0.29 & 350 & 420 \\
\hline
\end{tabular}


Table 2

Mechanical Properties of Socket Cap Screw and nut of ISO 898-1.

\begin{tabular}{lllllll}
\hline $\begin{array}{l}\text { Property } \\
\text { class }\end{array}$ & $\begin{array}{l}\text { Density } \\
\left(\mathrm{g} / \mathrm{cm}^{3}\right)\end{array}$ & $\begin{array}{l}E \\
(\mathrm{GPa})\end{array}$ & $\nu$ & $\begin{array}{l}\text { Proofload } \\
\mathrm{R}_{\mathrm{p} 0.2} \text { or Yield } \\
\text { strength } \\
(\mathrm{MPa})\end{array}$ & $\begin{array}{l}\text { UTS } \\
(\mathrm{MPa})\end{array}$ & $\begin{array}{l}\text { Breaking } \\
\text { torque } \\
(\mathrm{Nm})\end{array}$ \\
\hline 12.9 & 7.82 & 206.8 & 0.29 & 1100 & 1200 & $\begin{array}{l}39 \\
(29280 \mathrm{~N})\end{array}$ \\
\hline
\end{tabular}

process, the stress distribution on the connecting holes is important to evaluate whether the plastic deformation occurs. Thus, FEM gives an alternative to access and investigate whole stress distribution that cannot be examined. To conduct a tensile test with the MAF, firstly, the Arcan specimen should be assembled on the fixture halves with clamping jaws at a desired angle. The connecting bolts supply a certain fasten force to maintain the Arcan specimen firmly, which corresponds to a torque. A minimal applied torque introducing a sufficient compression prestress should be used, so that the slip of specimen form fixture halves can be prevented with bolts and knurl surfaces of clamping jaws. On the other side, Ref [9] pointed out that the excessive clamping force may induce detrimental stress concentrations in the specimen at the sides of the gauge section. Secondly, the specimen was loaded until rupture occurs. In this step, the case of pure tensile on fiber direction with loading angle $0^{\circ}$ are chosen to examine whole system as it is the critical case for all the connecting holes in the highest stress state.

\subsubsection{Stress evaluation of preloaded Arcan specimen}

Out of plane stress distribution around the clamping holes on the specimen after torque applied is show in Fig. 5. The stress distribution of whole fixture is presented in next section as the fasten stress induced by applied torque can be neglected in tensile direction. The clamping torque was chosen as $11.1 \mathrm{Nm}$ and $18.8 \mathrm{Nm}$. The out of plane stress $\sigma_{33}$ in Arcan specimen reaches $21 \mathrm{MPa}$ with higher applied torque especially around the connecting bolts, whereas $\sigma_{33}$ in the area contacted with knurl surfaces is slightly higher than the one with lower applied torque. The knurl surfaces of clamping jaws disperse the stress distribution effectively.
The contour of local stress along fiber direction $\sigma_{11}$ over the Arcan specimen is shown in Fig. 6 under tensile loading at the beginning of load application and the end. The maximum $\sigma_{11}$ on the specimen reaches 61.5 MPa around the clamping area with the torque of $18.8 \mathrm{Nm}$ applied. In the gauge area of the specimen, the stress $\sigma_{11}$ is $36 \mathrm{MPa}$ under compression. The UTS in fiber direction of the composite implemented in FEM is assumed as $1306 \mathrm{MPa}$, which is large enough for most common used composite configuration. The distribution of stress in the gauge area is quite normal with the optimized dimension. As increasing of the applied tension, the maximum stress transfer to the tip of notch root. Distributions of stress show that the peak stress near tip reaches much larger magnitudes than the average stress over the gauge section. The section variation that causes the stress concentration is referred to as a stress raiser. Theoretical stress concentration factor $K_{\mathrm{t}}$ in elastic range can be obtained as 2.38 in stress raiser form of opposite single V-shaped notches in finite-width plate [28] compared to 2.78, the value obtained numerically by FEM (max stress on normal stress).

$K_{t}=C_{1}+C_{2} \sqrt{K_{t u}}+C_{3} K_{t u}$

$K_{t u}=C_{1 u}+C_{2 u} \frac{2 h}{D}+C_{3 u}\left(\frac{2 h}{D}\right)^{2}+C_{4 u}\left(\frac{2 h}{D}\right)^{3}$

where $K_{\text {tu }}$ denotes U-shape raiser form and constants given by analogous formulas were calculated $C_{1 \mathrm{u}}=5.7, C_{2 \mathrm{u}}=-7.2, C_{3 \mathrm{u}}=3.9, C_{4 \mathrm{u}}=-1.38$, $C_{1}=-1.44, C_{2}=2.22, C_{3}=0.13 . h=19 \mathrm{~mm}$ and $D=63 \mathrm{~mm}$ are the dimensions of Arcan specimen.

When $\sigma_{11}$ reaches $1306 \mathrm{MPa}$, the simulation ceases. The normalized von Mises stresses against yield stresses of different parts of the fixture system were examined to ensure that obtained results are accurate with all parts working within an elastic phase to avoid irreversible plastic deformation.

\subsubsection{Stress evaluation of the entire fixture}

Two low-friction roller bearings are adopted in the guide units to minimizing the frictional resistance. The clamping system including two fixture halves, clamping parts and high stress bolts were studied with normalized stresses against yield stresses. Fig. 7 presents the distribution

Table 3

Transverse-isotropic material properties of Carbon fiber-Epoxy (UD).

\begin{tabular}{|c|c|c|c|c|c|c|c|c|c|}
\hline Areal density $\left(\mathrm{g} / \mathrm{cm}^{2}\right)$ & $E_{1}(\mathrm{GPa})$ & $E_{2}(\mathrm{GPa})$ & $E_{3}(\mathrm{GPa})$ & $G_{12}(\mathrm{GPa})$ & $G_{13}(\mathrm{GPa})$ & $G_{23}(\mathrm{GPa})$ & $\nu_{12}$ & $\nu_{13}$ & $\nu_{23}$ \\
\hline 1.54 & 137.0 & 8.2 & 8.2 & 5.5 & 5.5 & 3.1 & 0.277 & 0.277 & 0.32 \\
\hline
\end{tabular}

(a)
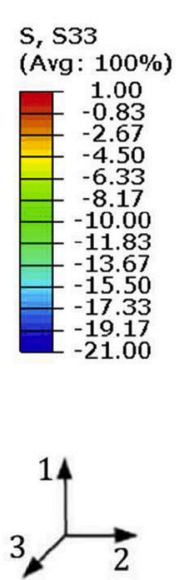

(b)

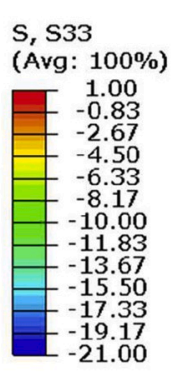

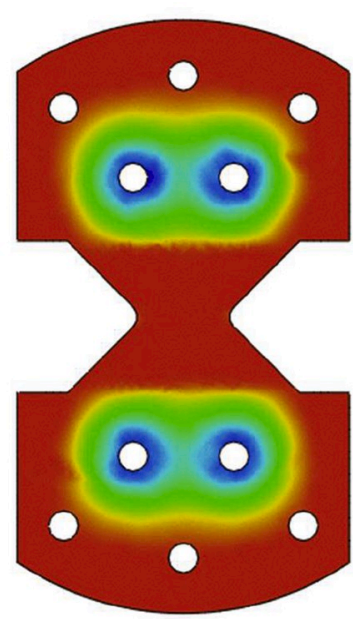

Fig. 5. Out of plane normal stress $\sigma_{33}$ in the specimen clamping area with a uniform bolt torque of (a) $11.1 \mathrm{Nm}$ and (b) $18.8 \mathrm{Nm}$. 
(a)

S, S11

(Avg: 100\%)

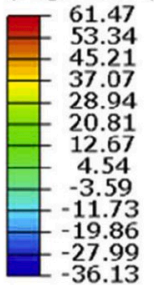

Max: 61.47

Node: ASN-1.180

Min: -36.13

Node: ASN-1.3684

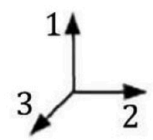

(b)

S, S11

(Avg: 100\%)

1305.79
1176.26
-1046.74
-917.21
-787.68
-658.15
-528.62
-399.10
269.57
140.04
10.51
-119.02
-248.54

Max: 1305.79

Node: ASN-1.103

Min: - 248.54

Node: ASN-1.1226

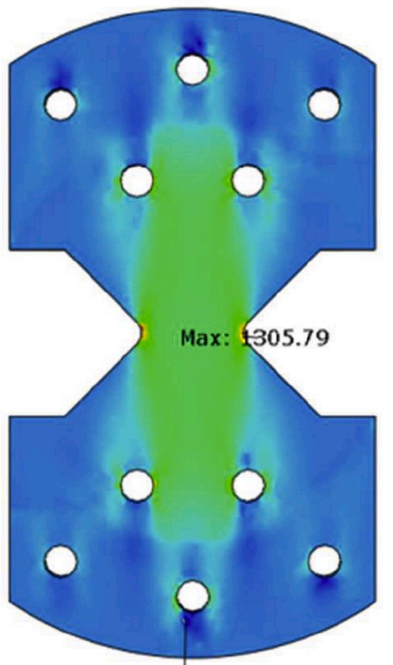

Fig. 6. Local stress along fibers $\sigma_{11}$ of the Arcan specimen: end of (a) preload and (b) tensile loading steps.

of normalized stresses in different parts. The plastic deformation is introduced as indicator reaching 1 . For fixture halves and clamping jaws, the UTS of $435 \mathrm{MPa}$ for T7351 was considered. The maximum indicator values are 0.88 and 0.37 around connecting holes for fixture halves and clamping jaws respectively. Bolts in high class properties are
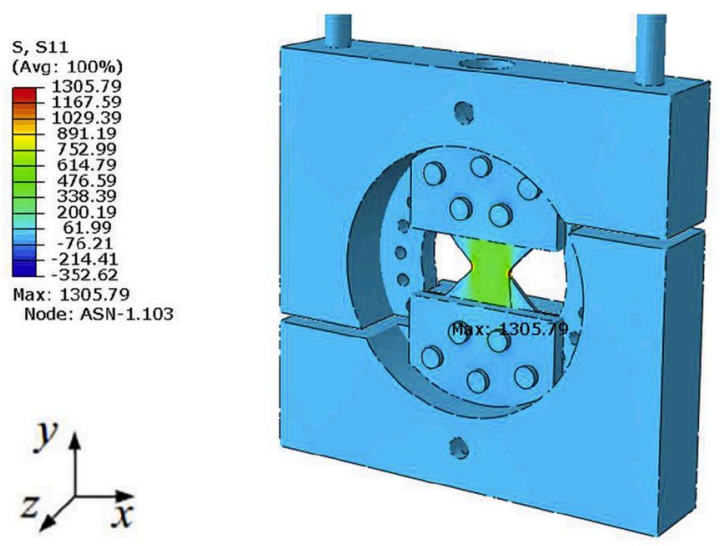

Normalized von MISES stress (435MPa), Mises (Avg: 100\%)
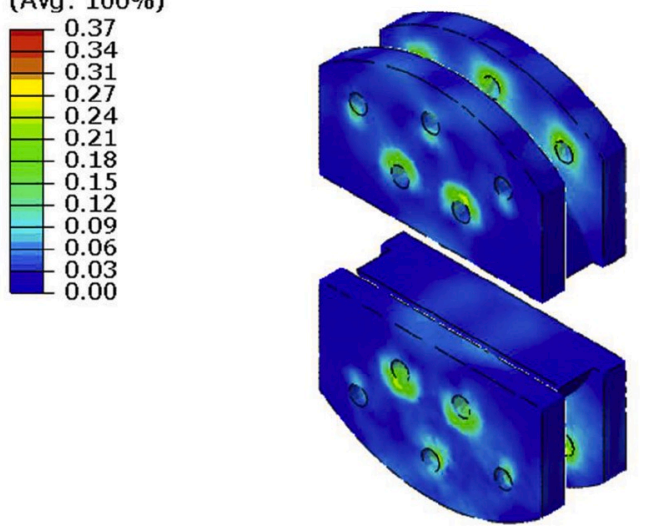

highly recommended as the indicator reach 0.93 with the proofload of $1100 \mathrm{MPa}$.

\subsubsection{Influence of notch radius on specimen stress distribution}

The normalized stress profiles along and across the specimen and

Normalized von MISES stress (435MPa), Mises (Avg: 100\%)
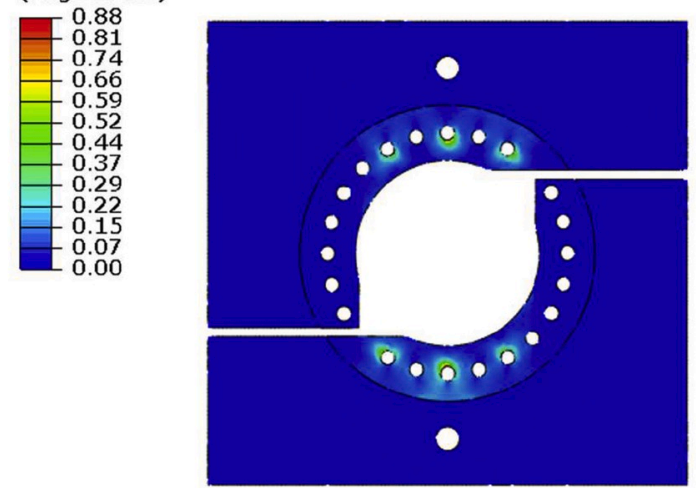

Normalized von MISES stress (1100MPa), Mises (Avg: 100\%)
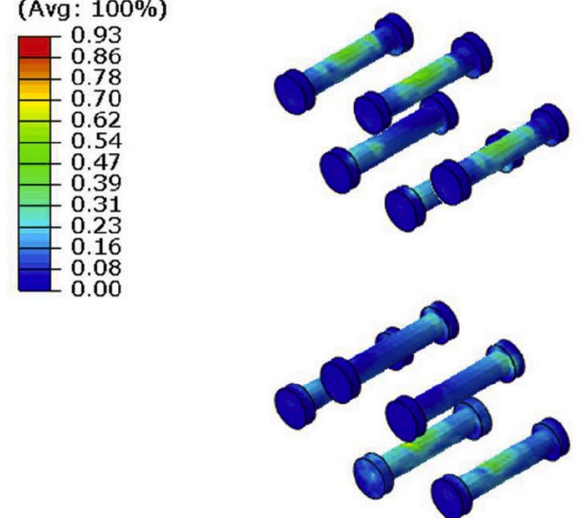

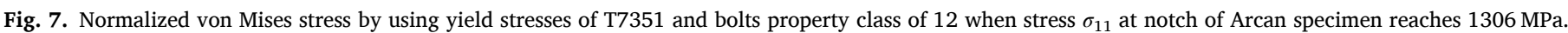


along the specimen notch for shear test have been studied by Ref. [13]. In this paper, biaxial loading boundary conditions with loading angle $45^{\circ}$ were applied on the simplified model (zone between clamping jaws) of Arcan specimen with stacking sequence of $[0 / 90]_{3 s}$. Python script was used to generate Arcan specimens with different geometry dimensions. The butterfly-shaped specimens with six different radii namely $0,1.27$, $2.38,3.54,4.78$ and $7 \mathrm{~mm}$ and a fixed notch angle $90^{\circ}$ were considered in the FEM. Elastic properties shown in Table 4 obtained via ASTM standard tests were implemented into the implicit simulation. Shear stresses normalized with the average shear stress calculated by dividing the applied load $F_{\mathrm{S}}$ with cross section area on the corresponding path were examined.

The normalized stresses along its notch are shown in Fig. 8. Notch radius affects the uniformity of stress distribution. All the curve shapes presented are nearly symmetric along the path, the curves with radii under $3.54 \mathrm{~mm}$ are concave like shapes, however, radii above $4.78 \mathrm{~mm}$ are inverse. The normalized stresses with notch radius of 3.54- and 4.78$\mathrm{mm}$ show more uniformity with a plateau in the middle zone along the gauge length. The errors between the maximum and minimum normalized stresses regardless of the stress concentration in the zone from $5 \mathrm{~mm}$ to $20 \mathrm{~mm}$ from left notch root are $4.51 \%(0.00), 3.57 \%$ (1.27), $2.00 \%$ (2.38), $2.31 \%$ (3.54), $0.78 \%$ (4.78) and $4.36 \%$ (7.00). The notch radius can be chosen between $3.54 \mathrm{~mm}$ and $4.78 \mathrm{~mm}$ according to the stress uniformity. Larger notch radius changes the position of stress concentration point. Therefore, notch radius of $3.54 \mathrm{~mm}$ was adopted.

\subsection{Biaxial mechanical response of a twill balanced composite}

The tests were performed on an electromechanical universal testing LR50K system with a $50 \mathrm{kN}$ capacity load cell and a standard head displacement rate of $2 \mathrm{~mm} / \mathrm{min}$ at $23 \pm 1{ }^{\circ} \mathrm{C}$ of standard laboratory condition. Shear and normal strains were extracted via Digital Image Correlation system (DIC) Vic2 $\mathrm{D}^{\mathrm{TM}}$ at the center gauge area of each specimen in ASTM and MAF tests. A series biaxial loading tests with angle step of 15-degree were conducted, and results show that rupture was caused by fiber breakage along 1-axis for all specimens. The fiber rotation in gauge area due to boundary condition of simple shear was detected by DIC method and this effect provide us a critical strain where fiber align to the principle tensile direction to determine the ultimate shear strength. The MAF was validated with ASTM standard tests in obtaining tensile and shear properties for an epoxy/twill woven-ply laminate.

Table 4

Comparison of the material properties of twill balanced woven composites [0/ 90] $_{3 \mathrm{~S}}$ using ASTM and MAF methods.

\begin{tabular}{|c|c|c|c|c|c|}
\hline \multirow{2}{*}{$\begin{array}{l}\text { Material } \\
\text { property }\end{array}$} & \multicolumn{2}{|l|}{ ASTM } & \multicolumn{2}{|l|}{ MAF } & \multirow{2}{*}{$\frac{\text { Error }}{\%}$} \\
\hline & $\begin{array}{l}\text { Average } \\
\text { value (c.v. } \\
\%)\end{array}$ & $\begin{array}{l}\text { Standard } \\
\text { deviation }\end{array}$ & $\begin{array}{l}\text { Average } \\
\text { value (c.v. } \\
\%)\end{array}$ & $\begin{array}{l}\text { Standard } \\
\text { deviation }\end{array}$ & \\
\hline $\begin{array}{l}E_{1}, E_{2} \\
\quad(\mathrm{GPa})\end{array}$ & $\begin{array}{l}84.15 \\
(2.58)\end{array}$ & 2.17 & $\begin{array}{l}60.96 \\
(15.75)\end{array}$ & 9.60 & 27.56 \\
\hline$G_{12}(\mathrm{GPa})$ & $4.60(3.38)$ & 0.16 & $5.51(5.40)$ & 0.30 & 19.93 \\
\hline$\nu_{12}$ & $\begin{array}{l}0.36 \\
(40.27)\end{array}$ & 0.15 & $\begin{array}{l}0.29 \\
(21.18)\end{array}$ & 0.06 & 19.44 \\
\hline $\begin{array}{l}X_{\mathrm{T}}, Y_{\mathrm{T}} \\
\quad(\mathrm{MPa})\end{array}$ & 847 (1.88) & 15.95 & $395(2.83)$ & 11.16 & 53.39 \\
\hline $\begin{array}{l}S_{12,5 \%} \\
\quad(\mathrm{MPa})\end{array}$ & 44 (1.54) & 0.68 & 57 (8.79) & 5.07 & 30.81 \\
\hline $\begin{array}{r}S_{12,}, 0.2 \% \\
(\mathrm{MPa})\end{array}$ & $24(8.47)$ & 2.08 & $39(20.00)$ & 7.86 & 60.10 \\
\hline$S_{12 \mathrm{c}}(\mathrm{MPa})$ & - & - & 45 (11.71) & 5.33 & $\begin{array}{l}3.22 \\
\left(S_{12},\right. \\
5 \%)\end{array}$ \\
\hline$\varepsilon_{12 \mathrm{c}}(\%)$ & - & - & $1.00(-)$ & - & - \\
\hline$\varepsilon_{1 \mathrm{u}}(\%)$ & $0.84(4.90)$ & 0.04 & $0.70(8.27)$ & 0.06 & 16.05 \\
\hline$\varepsilon_{12 \mathrm{u}}(\%)$ & $\begin{array}{l}15.78 \\
(19.82)\end{array}$ & 3.13 & $\begin{array}{l}13.05 \\
(25.32)\end{array}$ & 3.30 & 17.30 \\
\hline
\end{tabular}

\subsubsection{Mechanical response with different loading angles}

Load - displacement curves extracted directly from tensile machine for epoxy/twill composite with stacking $[0 / 90]_{3 s}$ are shown in Fig. 9. As the loading angle increased, maximum force decreased and the failure displacement increased. The main reason is that the combined stress state was introduced in biaxial loading. When it exceeds the material failure envelop, the material is expected to fail. The fibers in gauge area tend to rotate along the principle tensile direction. In $0^{\circ}$ pure tensile test, there was no fiber rotation as all fibers were already aligned in the tensile direction. In biaxial and pure shear tests, the fibers along 1-axis tend to lengthen, inducing a tensile stress as simple shear boundary conditions were applied. As the fibers rotate, large displacement was needed to reach the rupture. Fig. 10 shows the failure modes captured by crack evolution and finished with tensile breakage of fibers on 1-axis.

\subsubsection{The effect of fibers rotation on ultimate strength}

Herakovich et al. [29] predicted the tensile response of a $[ \pm 45]_{s}$ laminate by considering fiber rotation effect. The change of fiber orientation induced by deformation has a significant effect on the non-linear behavior of IM7/5260 and AS4/PEEK composite laminates [30]. In this paper, the failure mechanism modes were examined, as shown in Fig. 11, for $[0 / 90]_{3 s}$ woven ply laminates, it is indicated that plies with fibers along 2-axis underwent a transverse damage in matrix and failed first. The plies with fibers along 1-axis rotated following with the clamp movement as fibers in these plies were clamped between the fixture, which introduced rigid body rotation and resulted in simple shear stress state. In the final state, the constrained specimen also undertook tension as well as pure shear. The specimen ultimately failed with fiber breakage due to the tensile stress reached the axial limit of fibers. Fig. 9 shows the simple shear effects occurred in all specimens with fiber rupture under biaxial loading.

The rigid rotation angle was calculated by the difference between two angles (1) the one considering fiber movement against horizontal axis $\mathrm{x}$ and (2) DIC detected shear deformation zone with additional rigid rotation. Four specimens under shear load with loading angle $90^{\circ}$ were investigated in the effects of fiber rotation. Fig. 12 shows rigid rotation angle changes in stress-strain curves of specimens labeled with AP1S25, AP5S6, AP5S7 and AP5S9.

The shear strain $\varepsilon_{12}$ was selected as $2.5 \%$ corresponding to engineering strain $\gamma_{12} 5 \%$. As the rupture was not appeared, $S_{12}, 5 \%$ can be extracted according to ASTM D3518. However, the error between ASTM tests and MAF listed in Table 4 is large, it demonstrated that the shear strength derived from 5\% engineering shear strain for ASTM standard test is no more suitable for MAF. Furthermore, the fiber rotation detected via DIC increased nonlinearly until it closed to shear strain of $1 \%$ and a linear part appears. Less than shear strain $\varepsilon_{12}$ of $1 \%$, the mechanical response in gauge area is nearly pure shear and the shear deformation continues. The shear deformation finished as all fibers in gauge zone aligned with the tensile principle direction. In this critical point, shear deformation initiated in the rest zone between gauge area and clamping parts, which is represented by linear part of the fiber rotation curves. It can be also observed from the curly fibers outside of gauge zone along 1 -axis in Fig. 11 . Therefore, $S_{12 \mathrm{c}}$ derived from the critical point should be adopted as shear strength when using MAF.

\subsubsection{Validation of MAF compared with ASTM standard tests}

K. W. Gan [26] compared the uniaxial elastic modulus for glass/epoxy obtained from standard tests and a MAF. In this paper, Table 4 shows the obtained experiment results of full material property card obtained for twill woven-ply composite. Stress concentration factor $K_{\mathrm{t}}$ in elastic range for on-axis tensile load was calculated as 2.38 for the dimension of Arcan specimen adopted. Nominal tensile stress of $395 \mathrm{MPa}$ was amplified to a peak stress $940 \mathrm{MPa}$ compared to $847 \mathrm{MPa}$ obtained with ASTM D3039 unnotched tensile testing, with an error of $9.9 \%$. 
(a)

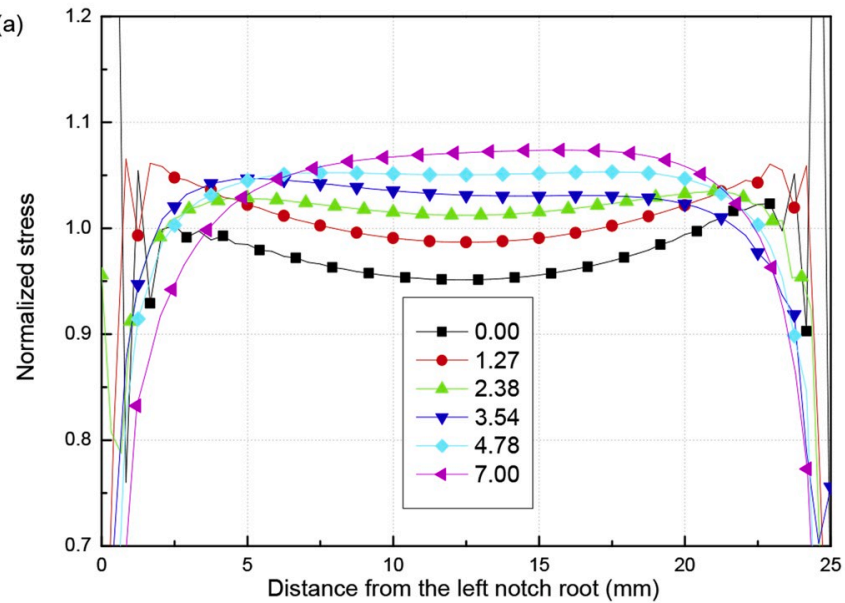

(b)

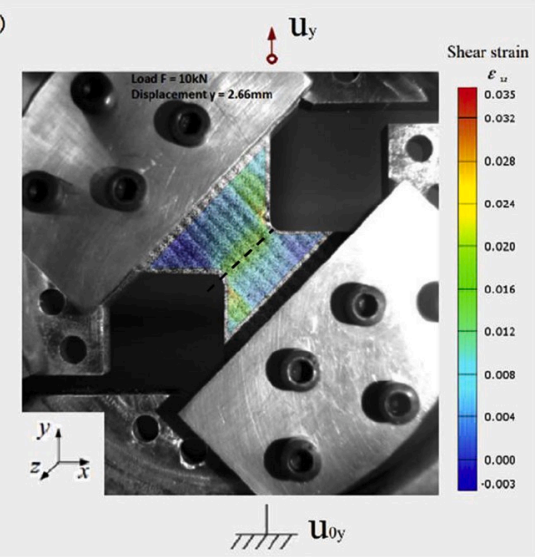

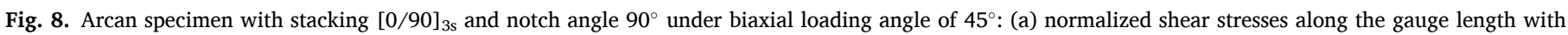
various notch radius and (b) Shear strain $\varepsilon_{12}$ extracted via DIC with notch radius $3.54 \mathrm{~mm}$.

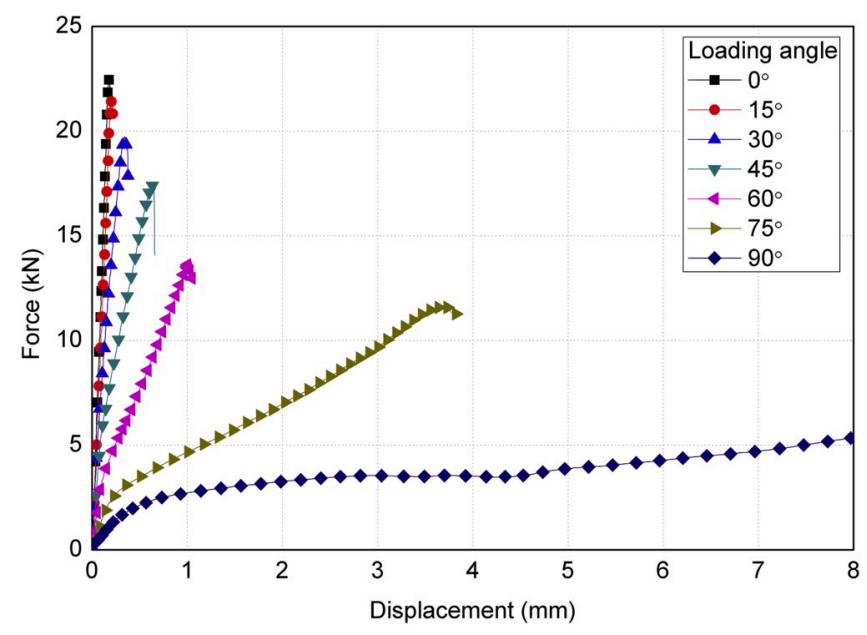

Fig. 9. Experimental load-displacement curves of different biaxial loading angles for $[0 / 90]_{3 s}$ Arcan specimens.

$\sigma_{\max }=K_{t} \cdot \sigma_{\text {nom }}$

where $K_{\mathrm{t}}$ denotes concentration factor for V-notch raiser form, $\sigma_{\max }$ and $\sigma_{\text {nom }}$ are the maximum and nominal stresses between the notch roots respectively.

It can be noticed that three shear strength $S_{12,5 \%} S_{12,0.2 \%}$ and $S_{12 \mathrm{c}}$ were used. $S_{12,5 \%}$ is calculated by maximum force at or below $5 \%$ engineering shear strain suggested by ASTM D3518, as maximum shear stress. $S_{12,0.2 \%}$, the offset shear strength and $S_{12 \mathrm{c}}$, the critical shear stress corresponding to the critical shear strain $\varepsilon_{12 \mathrm{c}}$ in MAF tests. The results show that $S_{12 \mathrm{c}}$ has good correspondence with $S_{12,5 \%}$ from ASTM tests with an error of $3.22 \%$ compared to $30.81 \%$ in $S_{12}$, 5\% and $60.10 \%$ in $S_{12}$, $0.2 \%$.

\section{Conclusion}

This work was carried out to develop a novel Modified Arcan Fixture (MAF) to conduct combined shear-tension/compression biaxial loading for fiber reinforced composites and hence to contributes raw biaxial experimental data for woven-ply composite in different biaxial loading angles to be used to validate constitutive models. The latest version of MAF and the specimen have been investigated in ABAQUS/Explicit with normalized stresses against yield stresses of each components. It proved that this solid structure has high resistance thanks to materials with superior strength adopted. Specimen dimension was studied and optimized with notch radius of $3.54 \mathrm{~mm}$ to obtain the most uniform stress state as possible under biaxial loading based on numerical studies.

The full material property card obtained with the MAF for twill woven ply composite was validated with ASTM results. The post treatment of experimental data for MAF was done by considering the fiber rotation detected via DIC. The fiber rotation effect during test was examined in shear and data were corrected according to the fiber rotate critical point. Results are agreed with the standard test. Biaxial response of woven ply composite was obtained. Failure modes show that fiber breakage is the main cause for all specimens with various loading angles.

The new designed MAF has several advantages:

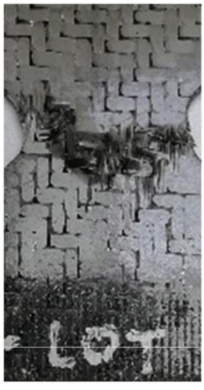

$\left(0^{\circ}\right)$

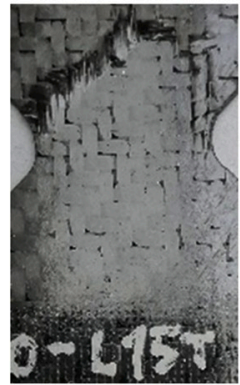

$\left(15^{\circ}\right)$

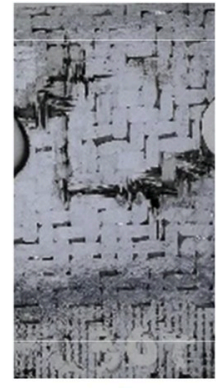

$\left(30^{\circ}\right)$

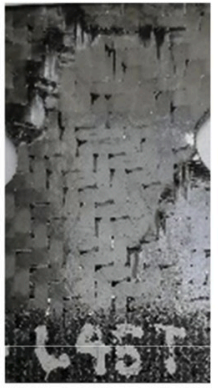

$\left(45^{\circ}\right)$

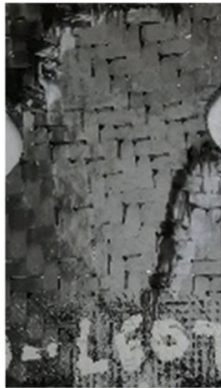

$\left(60^{\circ}\right)$

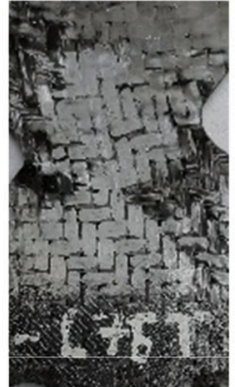

$\left(75^{\circ}\right)$

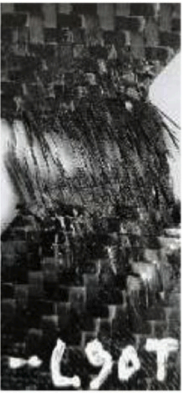

$\left(90^{\circ}\right)$

Fig. 10. Failure modes corresponding to the biaxial loading angles for $[0 / 90]_{3 s}$ Arcan specimens in the gauge zone. 


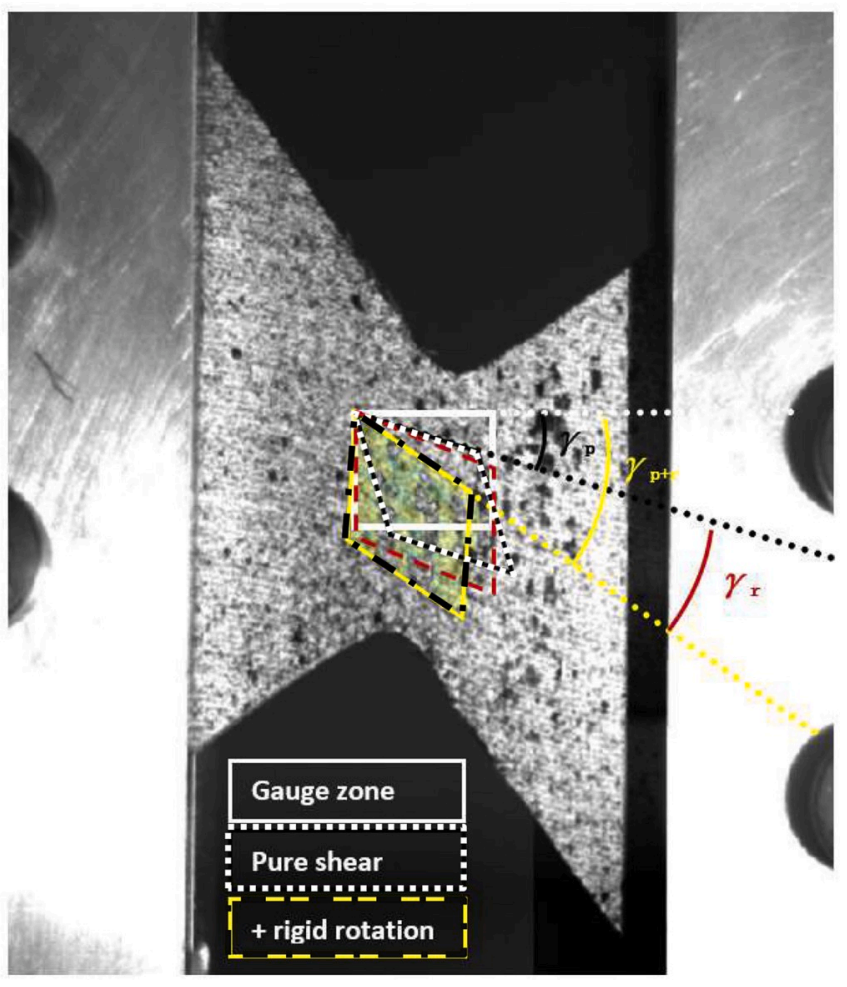

Fig. 11. Pure shear, simple shear and rigid rotation of plies with 0-degree fibers in a simple shear specimen of $[0 / 90]_{3 s}$.

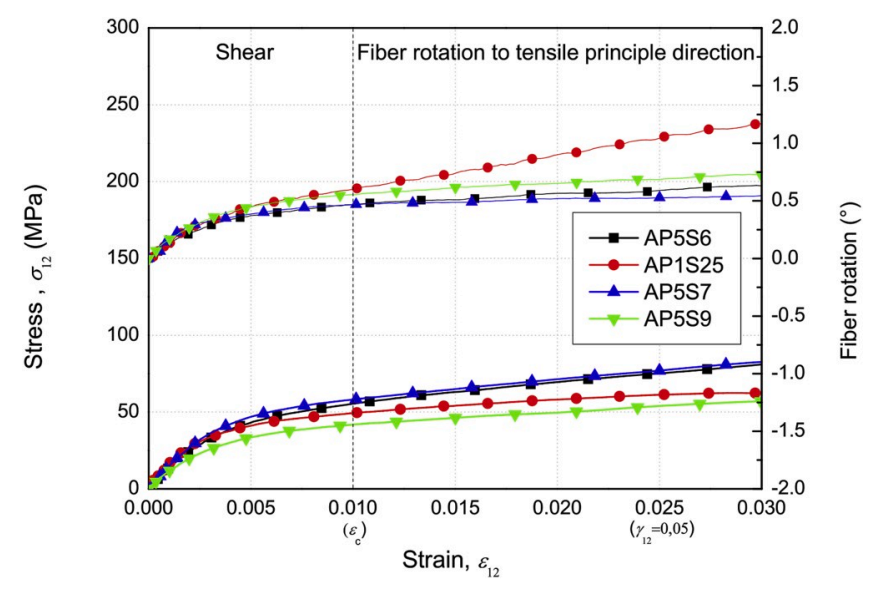

Fig. 12. Stress-strain curves of simple shear specimen of $[0 / 90]_{3 s}$ with rigid rotation angle changes.

a) It is easier to obtain biaxial stress state compared to other tests such as tubular specimen which is difficult to fabricate and cruciform specimen which needs sophisticate clamping system. Also, it is an alternative to the popular off-axis specimen.

b) It is inspired by V-notch rail and iosipescu tests for shear properties and takes advantages from both fixtures.

c) It consists of two fixture halves connecting with the guide units which ensure initial alignment and 10 connect holes keep the Arcan specimen in the desired loading direction before starting tests.

d) The clamping jaws prevented premature damage and shear out observed around connecting holes presented in literatures.

e) Combined tension (compression)/shear monotonic and fatigue tests can be conducted; The biaxial loadings can be applied easily, and angles of the applied loadings can be changed with a step of $15^{\circ}$. f) Loading angles can be changed easily thanks to the clamping system and a series of tests can be conducted efficiently and effortless.

g) Equipped with guide units to insure the in-plane stress states during quasi-static loading or fatigue loading and anti-buckling under compression

\section{Acknowledgements}

The first author (Pei Hao) and the second author (Israr Ud Din) are extremely grateful to their governments, China (China Scholarship Council, CSC) and, Pakistan (Higher Education Commission, HEC, in collaboration with Campus France) respectively. We acknowledge sincerely the financial support so that this research can be undertaken.

\section{References}

[1] ASTM D 6856/D 6856M, Standard guide for testing fabric-reinforced, Text. Compos. Mater. (2016).

[2] M. Hinton, A.S. Kaddour, P.D. Soden, Failure Criteria in Fibre Reinforced Polymer Composites: the World-wide Failure Exercise, Elsevier, 2004.

[3] A. Kaddour, M. Hinton, Input data for test cases used in benchmarking triaxial failure theories of composites, J. Compos. Mater. 46 (19-20) (2012) 2295-2312.

[4] A.S. Chen, F.L. Matthews, A review of multiaxial/biaxial loading tests for composite materials, Composites 24 (5) (1993) 395-406.

[5] D. Cai, G. Zhou, X. Wang, C. Li, J. Deng, Experimental investigation on mechanical properties of unidirectional and woven fabric glass/epoxy composites under offaxis tensile loading, Polym. Test. 58 (2017) 142-152.

[6] S. Amijima, T. Fujii, M. Hamaguchi, Static and fatigue tests of a woven glass fabric composite under biaxial tension-torsion loading, Composites 22 (4) (1991) 281-289.

[7] T. Shi, et al., Biaxial strength determination of woven fabric composite for airship structural envelope based on novel specimens, Compos. Struct. 184 (2018) 1126-1136.

[8] M. Gude, W. Hufenbach, M. Andrich, A. Mertel, R. Schirner, Modified V-notched rail shear test fixture for shear characterisation of textile-reinforced composite materials, Polym. Test. 43 (2015) 147-153.

[9] D.O. Adams, J.M. Moriarty, A.M. Gallegos, D.F. Adams, The V-notched rail shear test, J. Compos. Mater. 41 (3) (2007) 281-297.

[10] M. Arcan, Z. Hashin, A. Voloshin, A method to produce uniform plane-stress states with applications to fiber-reinforced materials, Exp. Mech. 18 (4) (1978) 141-146.

[11] A. Voloshin, M. Arcan, Failure of unidirectional fiber-reinforced materials-new methodology and results, Exp. Mech. 20 (8) (1980) 280-284.

[12] K.W. Gan, T. Laux, S.T. Taher, J.M. Dulieu-Barton, O.T. Thomsen, A novel fixture for determining the tension/compression-shear failure envelope of multidirectional composite laminates, Compos. Struct. 184 (2018) 662-673.

[13] S.C. Hung, K.M. Liechti, Finite element analysis of the Arcan specimen for fiber reinforced composites under pure shear and biaxial loading, J. Compos. Mater. 33 (14) (1999) 1288-1317.

[14] J.Y. Cognard, L. Sohier, P. Davies, A modified Arcan test to analyze the behavior of composites and their assemblies under out-of-plane loadings, Compos. Part Appl. Sci. Manuf. 42 (1) (2011) 111-121.

[15] M. Nikbakht, N. Choupani, Fracture toughness characterization of carbon-epoxy composite using Arcan specimen, Int. J. Aerosp. Mech. Eng. 2 (2008) 247-253.

[16] S.T. Taher, O.T. Thomsen, J.M. Dulieu-Barton, S. Zhang, Determination of mechanical properties of PVC foam using a modified Arcan fixture, Compos. Part Appl. Sci. Manuf. 43 (10) (2012) 1698-1708.

[17] C. Li, A. Cantarel, X. Gong, Influence of structural parameters at microscale on the fiber reinforcement, J. Compos. Mater. 53 (7) (2019) 863-872.

[18] Y. Liu, I. Straumit, D. Vasiukov, S.V. Lomov, S. Panier, Prediction of linear and nonlinear behavior of 3D woven composite using mesoscopic voxel models reconstructed from X-ray micro-tomography, Compos. Struct. 179 (2017) 568-579.

[19] I. Ud Din, S. Panier, P. Hao, G. Franz, J. Bijwe, L. Hui, Finite element modeling of indentation and adhesive wear in sliding of carbon fiber reinforced thermoplastic polymer against metallic counterpart, Tribol. Int. 135 (2019) 200-212.

[20] K. Ahmed, B.K. Paul, M.A. Jabin, B. Biswas, FEM analysis of birefringence, dispersion and nonlinearity of graphene coated photonic crystal fiber, Ceram. Int. 45 (12) (2019) 15343-15347.

[23] ASTM D 3039/D 3039M, Standard Test Method for Tensile Properties of Polymer Matrix Composite Materials, 2017.

[24] ASTM D 3518/D 3518M, Standard Test Method for In-Plane Shear Response of Polymer Matrix Composite Materials by Tensile Test of a $\pm 45^{\circ}$ Laminate, 2018.

[25] M. Arcan, The iosipescu shear test as applied to composite materials: Discussion, Exp. Mech. 24 (1) (1984) 66-67.

[26] T. Laux, K.W. Gan, J.M. Dulieu-Barton, O.T. Thomsen, A simple nonlinear constitutive model based on non-associative plasticity for UD composites: development and calibration using a Modified Arcan Fixture, Int. J. Solids Struct. 162 (2019) 135-147.

[27] D.F. Adams, D.E. Walrath, Further development of the losipescu shear test method, Exp. Mech. 27 (2) (1987) 113-119. 
[28] W.D. Pilkey, D.F. Pilkey, R.E. Peterson, Peterson's Stress Concentration Factors, third ed., John Wiley, Hoboken, N.J, 2008.

[29] C.T. Herakovich, R.D. Schroedter, A. Gasser, L. Guitard, Damage evolution in $[ \pm 45]$ s laminates with fiber rotation, Compos. Sci. Technol. 60 (15) (2000) 2781-2789.
[30] C.T. Sun, C. Zhu, The effect of deformation-induced change of fiber orientation on the non-linear behavior of polymeric composite laminates, Compos. Sci. Technol. 60 (12) (2000) 2337-2345. 